\title{
Case Study: Effect of Handrim Diameter on Performance in a Paralympic Wheelchair Athlete
}

\author{
Gabriel Brizuela Costa, Miguel Polo Rubio, Salvador Llana \\ Belloch, and Pedro Pérez Soriano \\ University of Valencia
}

\begin{abstract}
This study, with a top T-52 class athlete, determines the relationship between stroke frequency (SF) and push time (PT) and wheelchair velocity (Wv) using different handrim diameters (HD) and the effect of different HDs on the athlete's heart rate (HR) and blood lactate (LACT) at competition speeds. Wv shows a linear-direct relationship with SF but a linear-inverse relationship with PT ( $p<.001$ in both cases). Using bigger handrims $(0.37 \mathrm{~m}$ instead of $0.36 \mathrm{~m})$, SF increases $6 \%$, while PT decreases $27 \%\left(\right.$ at $\left.24 \mathrm{Km} \cdot \mathrm{h}^{-1}\right)$. HR $(p<.0001)$ increases with $\mathrm{Wv}$ and is also affected by HD with differences between the $0.34 \mathrm{~m}-0.36 \mathrm{~m}$ handrim group (lower values) and the $0.37 \mathrm{~m}$ handrim (higher values). Significant interaction $(p<.0001)$ is identified between HD and Wv. LACT results seem to follow the same direction as HR. This methodology helped the athlete to choose the optimum HD, and his achievements (some world records) indicate that HD optimization could be highly profitable in sport terms.
\end{abstract}

Attaining peak performance in sports generally requires not only great care of many aspects in everyday life and an adequate planning of training but also constant work in optimizing small details that can often make the difference between real success and a good result. In wheelchair athletics, paying attention to the equipment, especially the wheelchair and its components, seems to be relevant, but research is actually more focused on mechanical efficiency in relation with the mechanical power that the athlete can produce, a great deal of which is lost (frequently more than 90\%; Woude, Groot, Hollander, Schenau, \& Rozendal, 1986; Woude, Veeger, \& Dallmeijer, 2000), the rest being transferred onto the wheels, adding to propulsion.

For some time now, researchers like Woude, Veeger, Rozendal, and Sargeant (1989); Veeger et al. (1989); Wang, Deutsch, Morse, Hedrick, and Millikan (1995); and Goosey and Campbell (1998) have argued that as wheelchair velocity increases, the total duration of each stroke cycle drops significantly, mainly as a

The authors are with the University of Valencia, Department of Sports and Physical Education in Valencia Spain. Miguel Polo is also with Polytechnic University of Valencia, Vice-rectorate for Sports. 
result of a reduction in push time. Then, when an athlete wants to increase wheelchair velocity, he/she must apply a greater mechanical impulse (the integral of a force with respect to time or could be understood as the change in wheelchairathlete system momentum) in a shorter push time and at a hand's higher linear velocity, at least to increase the stroke frequency much more.

The higher the stroke frequency, the greater the energy cost. An increased hand linear velocity, as a result of higher frequencies, will probably lead to enhanced cardiorespiratory stresses (Woude et al., 1988). Higher stroke frequencies also affect both heart rate and blood lactate, increasing both variables (Woude et al., 1989; Goosey et al., 2000), and can hamper performance in endurance races (Okawa et al. 1999; Chow et al., 2001). Wheelchair propulsion techniques would be more efficient at lower cycle frequencies, with longer push times and a greater amount of mechanical work per cycle.

Goosey et al. (1997) studied propulsion in $800 \mathrm{~m}$ wheelchair athletes with different performance levels, concluding that top racers reached higher speeds due to the greater amplitude of their strokes (displacement produced by the wheelchair in each stroke). The authors also concluded that younger athletes performed worse mainly as a result of a shorter push times.

\section{The Handrim}

In spite of the low mechanical performance of propulsion via handrims (Figure 1), almost all wheelchair sports use this standard propulsion element, which was fitted onto both wheels.

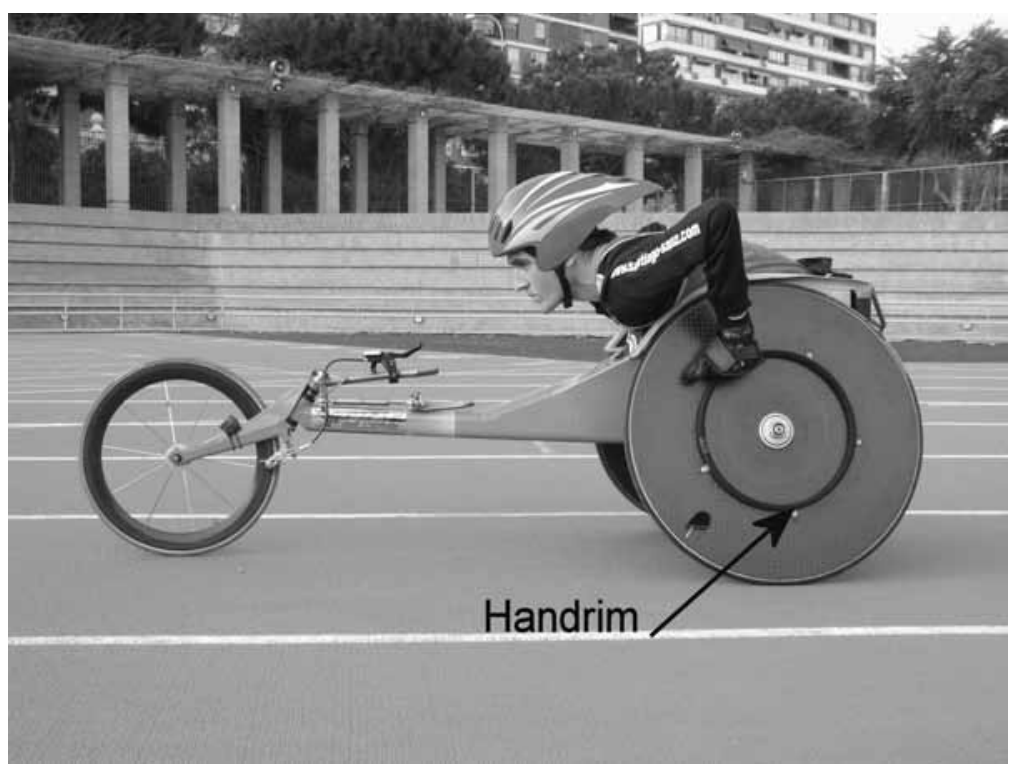

Figure 1 - Propulsion handrim on an athletics wheelchair. 
Woude et al. (1988) investigated the effect of five handrim diameters $(0.3$ $\mathrm{m}-0.56 \mathrm{~m})$ during wheelchair ambulation at different velocities $\left(0.83 \mathrm{~m} \cdot \mathrm{s}^{-1}-4.17\right.$ $\mathrm{m} \cdot \mathrm{s}^{-1}$ ) in eight male wheelchair sportsmen on a motor driven treadmill. The authors failed to find handrim diameter effects on stroke cycle time but found a statistical increase in cycle frequency with the velocity and an associated decrease in push time. Woude et al. (1988) also concluded that smaller handrims reduce cardiorespiratory stress.

Evidence indicates that the use of smaller diameters increases the mechanical efficiency of propulsion of a wheelchair. As Veeger et al. (1992) and Woude et al. (1988) argue, the higher speed of the hand-needed to attain propulsion with a larger diameter handrim (due to its greater tangential velocity) — could be a determining factor of lower performance.

When greater torque is needed, however, e.g., going uphill or for rapid speed increases, a larger diameter could be more effective. Guo et al., (2006) studied the effect of the diameter of the propulsion handrim $(0.54 \mathrm{~m}, 0.43 \mathrm{~m}$, and $0.32 \mathrm{~m})$ on the propulsive moment generated by healthy individuals on standard wheelchairs. They found out that the kinetic, potential, and total mechanical energy delivered in a complete propulsion cycle with the large handrims were significantly greater than with the small ones. Nevertheless the authors conclude that propelling the wheelchair with the larger handrim size will have a greater metabolic cost.

Based on the above and taking into account the conclusions drawn by McLaurin and Brubaker (1991), Veeger et al. (1992), Traut and Schmauder (1993), and Woude et al. (2000), the diameter of a wheelchair handrim could be assumed to be equivalent to the gears on a bicycle and so different conditions would request different handrim sizes. Better performing athletes can require greater gear development (the distance a bicycle travels with one pedal revolution) or different handrim diameters (in wheelchair athletics) that can help them move faster, while those with lower performance levels will need less development or rollout.

In addition, one must consider that the individual capabilities of wheelchair athletes, meaning the impact of their impairment on the activity, can be very different. Therefore, it should be logical to conclude that the election of the handrim diameter for competition must be carried out in a very individualized way.

\section{Objectives}

The objectives of this study were, first, to determine the relationship between stroke frequency and push time (dependent variables) and wheelchair velocity (manipulated intensities) using two different handrim diameters and, second, to determine the athlete's physiological response, measured as heart rate and blood lactate (dependent variables) with three different handrim diameters at three different competition speeds.

We also aimed to apply the results obtained to optimize the performance of a top-level Paralympics athlete (functional class T-52) with partial quadriplegia caused by the Charcot-Marie Tooth neuromuscular disease. 


\section{Method}

\section{Participants}

This paper presents a single-case study conducted on an elite Paralympic athlete, of functional class T-52, male, aged $26,1.76 \mathrm{~m}$ tall, $52 \mathrm{Kg}$, trained for 13 years and the winner of four medals (silver and bronze) in the Paralympic Games (Sydney, 2000 and Athens, 2004) and four gold medals in the last World Athletics Championship held in Assen in 2006.

The athlete studied has had an IPC (International Paralympic Committee) permanent functional classification, since the start of his athletics career. The origin of his disability is a neuropathic disease (Charcot-Marie Tooth, type II), which impairs the strength of his distal musculature. He has muscular atrophy on his forearms, hands, thighs, legs and feet, and moderate muscular atrophy on his arms. His muscular strength levels scored 4 on the ASIA scale for the proximal musculature of upper and lower limbs and 0 on fingers and toes. EMG examination showed arreflexia, absence of sensitivity on the median nerve, and axonal neuropathy, with a normal distal latency on the axillary nerve.

The subject gave his written consent to take part in the study and to publish the results and conclusions. The protocols were developed conform to the ethic principles of the University of Valencia and the CIOMS (Council for International Organizations of Medical Sciences).

The same wheelchair was used for all sections of the study, i.e., an Eagle Sports Chairs athletics wheelchair, model S 606; the handrim was the only changed element, as described in different chapters in this paper.

In all experiments, the athlete used Harness flexible gloves, 2-Pocket Mitt Quad type, with a rubber push surface, frequently used by quadriplegic athletes.

\section{Studies}

Two propulsion studies were conducted: a biomechanical study and a physiological one. The first study analyzed the evolution of stroke frequency and push time, using two different handrim sizes at eleven different wheelchair velocities. The second study focused on the effect of three different handrim diameters on heart rate and blood lactate concentration at three different wheelchair velocities that were very close to competition ones.

\section{Biomechanical Study of Propulsion}

Variables. The dependent variables in this first study were "stroke frequency" (SF) and "push time" (PT), measured for different levels of the independent variable "wheelchair velocity" (Wv) under two "handrim diameter" (HD) conditions: $0.36 \mathrm{~m}$ and $0.37 \mathrm{~m}$. Wv was set at $12,15,18,21$, and $24 \mathrm{Km} \cdot \mathrm{h}^{-1}$ for the $0.36 \mathrm{~m}$ handrim condition and at $12,14,16,18,20,22$, and $24 \mathrm{Km} \cdot \mathrm{h}^{-1}$ for the $0.37 \mathrm{~m}$ condition.

Measurement Instruments. To measure SF and Wv, an S-VHS PAL video system was used (Panasonic DGP800 video camera and Panasonic AG-7700 
VCR), used as an optical-electronic timekeeping system, with 0.02 s time resolution (from 50 deinterlaced fields per second).

To measure PT, a digital high-speed video camera (Redlake Imaging Series Motion Scope, PCI 1000S model) was used with $480 \times 420$ pixel spatial resolution and 8 bits color depth, capturing at a $500 \mathrm{~Hz}$ recording frequency, resulting in a $0.002 \mathrm{~s}$ time resolution.

To obtain images with the high speed camera, the athlete was followed by a quad bike (four-wheel motorcycle) around the track. The computer equipment needed to connect the camera was installed onto a trailer and pulled by the quad. The camera was fitted onto the wheelchair itself in such a way that details of the hand-handrim contact phase could be recorded.

To control Wv, we used the same video system that was used for determining SF, controlling passage time in each $400 \mathrm{~m}$ lap, while for the feedback of this variable by the athlete a Sigma BC 1106 speedometer (with a resolution of $0.1 \mathrm{Km}^{\circ} \mathrm{h}^{-1}$ ) was installed on the wheelchair.

Development of the Experiments. Two similar experiments were conducted on an athletics racing track $(400 \mathrm{~m})$ with a 15 -day interval. The athlete was asked to keep a constant speed along one lap $(400 \mathrm{~m})$, which was controlled by the researcher.

In the first test-with $0.37 \mathrm{~m}$ handrims (14.5 inches) - a total of 7 measurements were taken, starting at $12 \mathrm{Km} \cdot \mathrm{h}^{-1}$, increasing $2 \mathrm{Km} \cdot \mathrm{h}^{-1}$ each series, and finishing at $24 \mathrm{Km} \cdot \mathrm{h}^{-1}$. In the second test the athlete used $0.36 \mathrm{~m}$ rims (14 inches). As we thought this could take longer, he started at $12 \mathrm{Km} \cdot \mathrm{h}^{-1}$ but continued with $3 \mathrm{Km} \cdot \mathrm{h}^{-1}$ increases until $24 \mathrm{Km} \cdot \mathrm{h}^{-1}$.

Each repetition started with a $200 \mathrm{~m}$ launched start during which the athlete progressively reached the preset speed. The recovery time between repetitions was of $3 \mathrm{~min}$, enough time to recover after an exercise of intensity lower (almost all of the repetitions) than his anaerobic threshold.

Data Processing. To obtain SF values, the recorded video images were played in a professional VCR (with a time-code reader). The time needed to complete 5 strokes (on the last straight stretch of the track) was measured at each speed.

To obtain PT values, based on the primary data provided by the high-speed video camera (Figure 2), the number of frames in which the hand was in contact with the handrim was counted and PT was calculated (multiplying the number of frames by $0.002 \mathrm{~s} \cdot$ frame $^{-1}$ ).

Statistical Methods. A linear regression analysis was carried out for SF and PT as dependent variables in relation with independent variable $\mathrm{Wv}$ and separately for each HD value. An Alpha significance level of 0.05 was set.

\section{Physiological Study of Propulsion}

Variables. The dependent variables in the second study were "heart rate" during the effort (HR) and "blood lactate concentration" at $30 \mathrm{~s}$ after the effort (LACT) under three conditions of the independent variable "handrim diameter" (HD): $0.34 \mathrm{~m}, 0.36 \mathrm{~m}$ and $0.37 \mathrm{~m}$, and three conditions of the second independent variable "wheelchair velocity" (Wv): $20 \mathrm{Km} \cdot \mathrm{h}^{-1}, 22 \mathrm{Km} \cdot \mathrm{h}^{-1}$, and $24 \mathrm{Km} \cdot \mathrm{h}^{-1}$. At the 

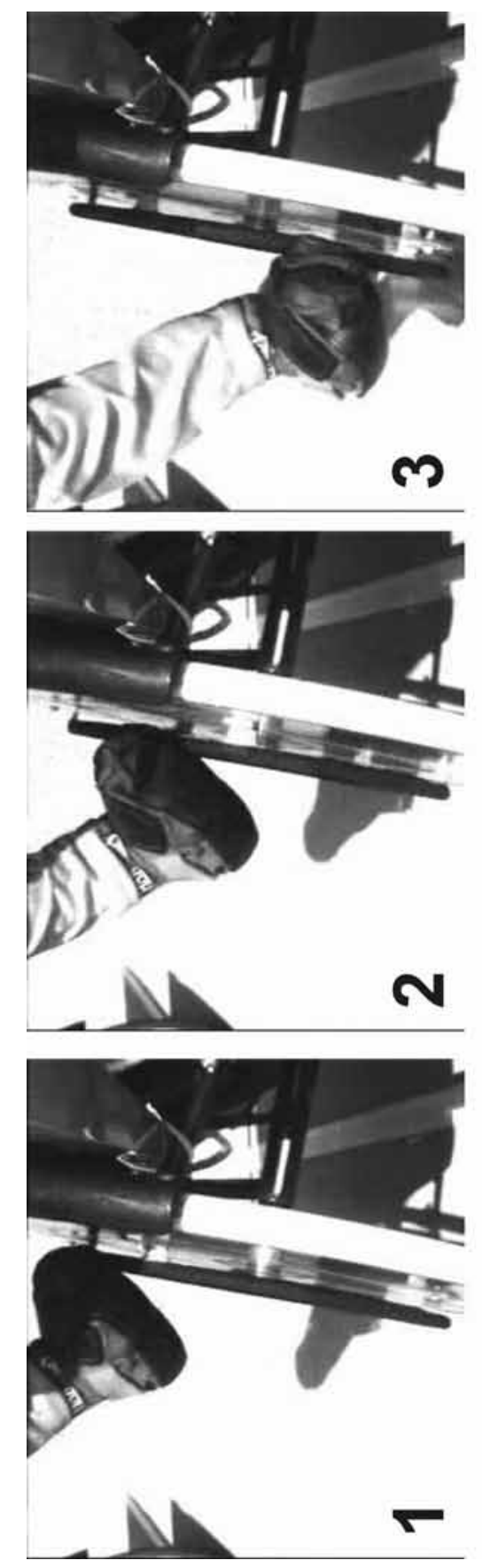

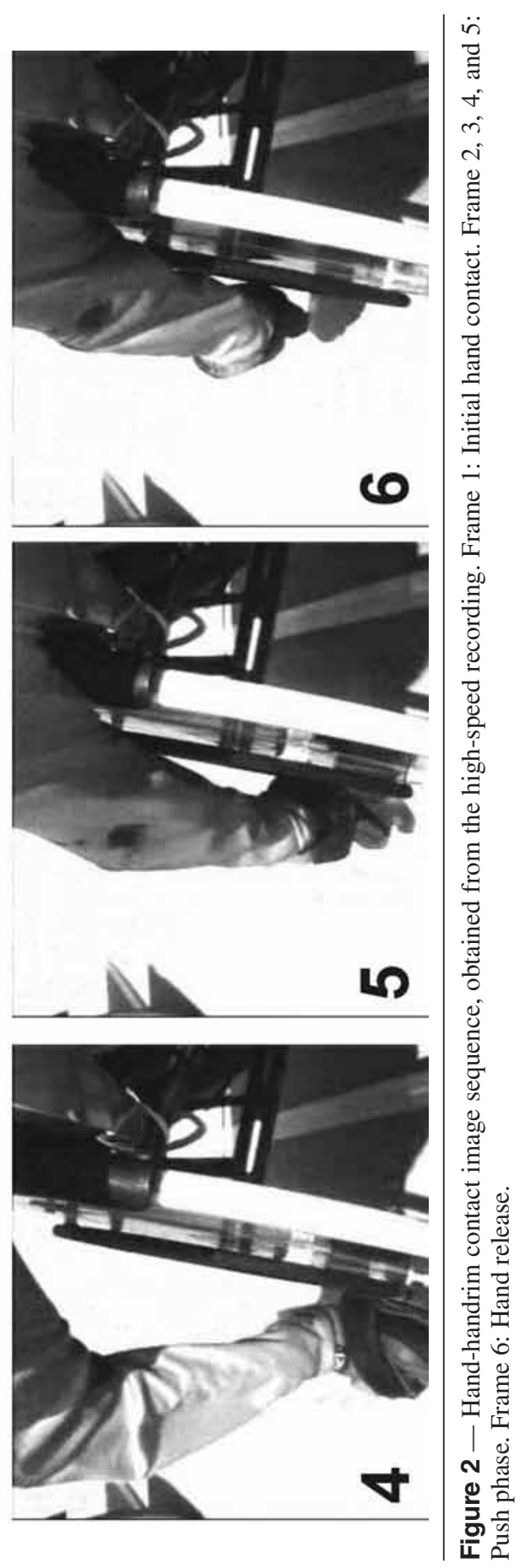


moment of the test the athlete used $0.37 \mathrm{~m}$ handrims and his anaerobic threshold was set around $23 \mathrm{Km} / \mathrm{h}$.

Measurement Instruments. To record HR a Polar XTrainer Plus heart rate monitor was used, together with a Polar Interface Plus (Polar Electro OY Finland). HR was recorded at a $0.2 \mathrm{~Hz}$ sampling frequency.

Wv and subject feedback were measured using the same instruments used in the biomechanical analysis, while LACT was measured by means of a LACTATEPRO portable lactate analyzer.

Development of the Experiments. An experiment was designed to determine physical strain in terms of heart rate (HR) and blood lactate (LACT; Janssen, Dallmeijer, \& Woude, 2001) caused by the use of three different handrims (HD) at three different wheelchair velocities (Wv).

First, the athlete warmed up by doing a 15-min race, some mild stretching, and some short series up to $24 \mathrm{Km} \cdot \mathrm{h}^{-1}$, this being the maximum speed to be kept in the test.

After an 8-min recovery period, a total of nine 5-min series were completed, randomly alternating 3 different handrim diameters: $0.34 \mathrm{~m}$ (13.5 inches), $0.36 \mathrm{~m}$ (14 inches), and $0.37 \mathrm{~m}$ (14.5 inches), respectively and 3 speeds: $20 \mathrm{Km} \cdot \mathrm{h}^{-1}, 22$ $\mathrm{Km} \cdot \mathrm{h}^{-1}$, and $24 \mathrm{Km} \cdot \mathrm{h}^{-1}$.

Based on information supplied by the coach for the time of the season when the experiments were conducted, the two lowest speeds required an intensity effort under the athlete's anaerobic threshold (maximum exercise intensity theoretically bearable by the athlete for long periods) and the highest one required an intensity level that surpassed this threshold. Please note that in the three weeks before the test, the athlete alternated the use of the three diameters in his training schedule to get used to them.

The athlete started the series with mild acceleration for $200 \mathrm{~m}$ before reaching the preset speed of each series. This was done to prevent sudden acceleration from inducing a higher blood lactate concentration than the one needed for the required effort. Ten min recovery intervals between series were included to allow blood lactate removal and to change handrims.

Statistical Methods. With the HR data obtained throughout the repetitions, a Multifactor Analysis of Variance (MANOVA) was done to find significant HR differences in relation with $\mathrm{Wv}_{\mathrm{v}}$ (levels: $20 \mathrm{Km} \cdot \mathrm{h}^{-1}, 22 \mathrm{Km} \cdot \mathrm{h}^{-1}$, and $24 \mathrm{Km} \cdot \mathrm{h}^{-1}$ ) and HD (levels: $0.34 \mathrm{~m}, 0.36 \mathrm{~m}, 0.37 \mathrm{~m}$ ) and to determine interaction between both factors. An Alpha significance level of 0.05 was set.

\section{Results}

\section{Biomechanical Study of Propulsion}

As shown in Figure 3, a linear and direct relationship was found between SF and $\mathrm{Wv}(r=.9727$ for HD $=0.37 \mathrm{~m} ; r=.9629$ for $\mathrm{HD}=0.36 \mathrm{~m} ; p<.0001$ in both cases) in such a way that SF increased as Wv increased. In addition, a linear though inverse relationship was found between PT and Wv $(r=-0.9821$ for HD $=$ 


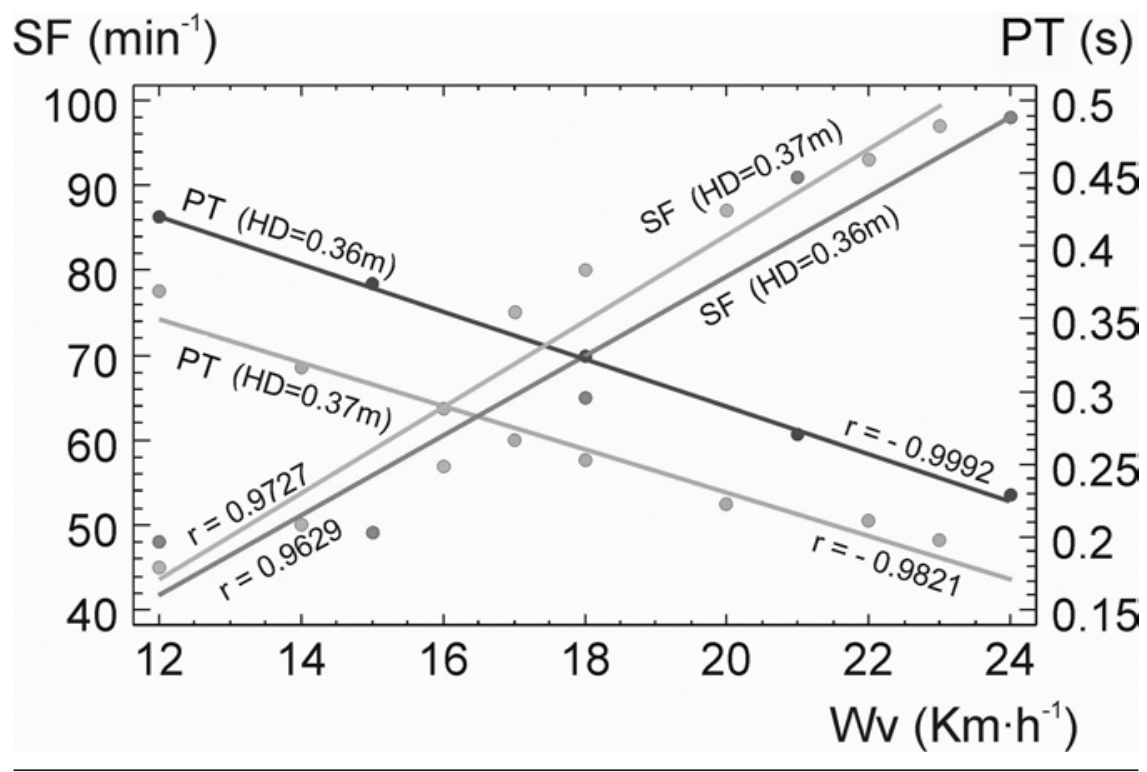

Figure 3 - Summary of biomechanical findings. Regression analysis for SF (stroke frequency) and PT (push time) with Wv (wheelchair velocity) for two different HDs (0.36 m and $0.37 \mathrm{~m})$.

$0.37 \mathrm{~m} ; \mathrm{r}=-0.9992$ for $\mathrm{HD}=0.36 \mathrm{~m} ; p<.0001$ in both cases) in such a way that PT decreased as Wv rose.

Analyzing the data of the performed regression analysis, it can be concluded that at a lower $\mathrm{Wv}\left(12 \mathrm{Km} \cdot \mathrm{h}^{-1}\right)$ differences in SF, caused by an increase in HD (from $0.36 \mathrm{~m}$ to $0.37 \mathrm{~m}$ ), were about $4 \%$. At the highest velocities $\left(24 \mathrm{Km} \cdot \mathrm{h}^{-1}\right)$ the differences were $6 \%$. In addition, greater differences were identified for the PT variable. While at the lowest $\mathrm{Wv}\left(12 \mathrm{Km} \cdot \mathrm{h}^{-1}\right)$, PT was reduced by $18 \%$ with the bigger handrim and at the highest velocity $\left(24 \mathrm{Km} \cdot \mathrm{h}^{-1}\right)$; this reduction in push time went up to $27 \%$.

\section{Physiological Study of Propulsion}

In general terms, HR is affected in a statistically significant way $(p<.0001)$ by both variables $\mathrm{Wv}$ and HD (Table 1). The multiple range test (post hoc LSD) revealed HR differences between the three Wv levels $\left(20 \mathrm{Km} \cdot \mathrm{h}^{-1}, 22 \mathrm{Km} \cdot \mathrm{h}^{-1}\right.$, and $24 \mathrm{Km} \cdot \mathrm{h}^{-1}$ ), while differences in HD were only found between the $0.34 \mathrm{~m}$ and $0.36 \mathrm{~m}$ handrim diameter group and the $0.37 \mathrm{~m}$ handrim. Nevertheless, significant interaction $(p<.0001)$ was found between HD and Wv.

It must be emphasized that the athlete failed to keep the highest speed (24 $\left.\mathrm{Km} \cdot \mathrm{h}^{-1}\right)$ with the biggest handrims $(0.37 \mathrm{~m})$.

With just a single sample obtained for each series, the LACT variable cannot be statistically analyzed. However, blood lactate results appear to point to the same direction as the statistical findings obtained for HR (Table 1). 


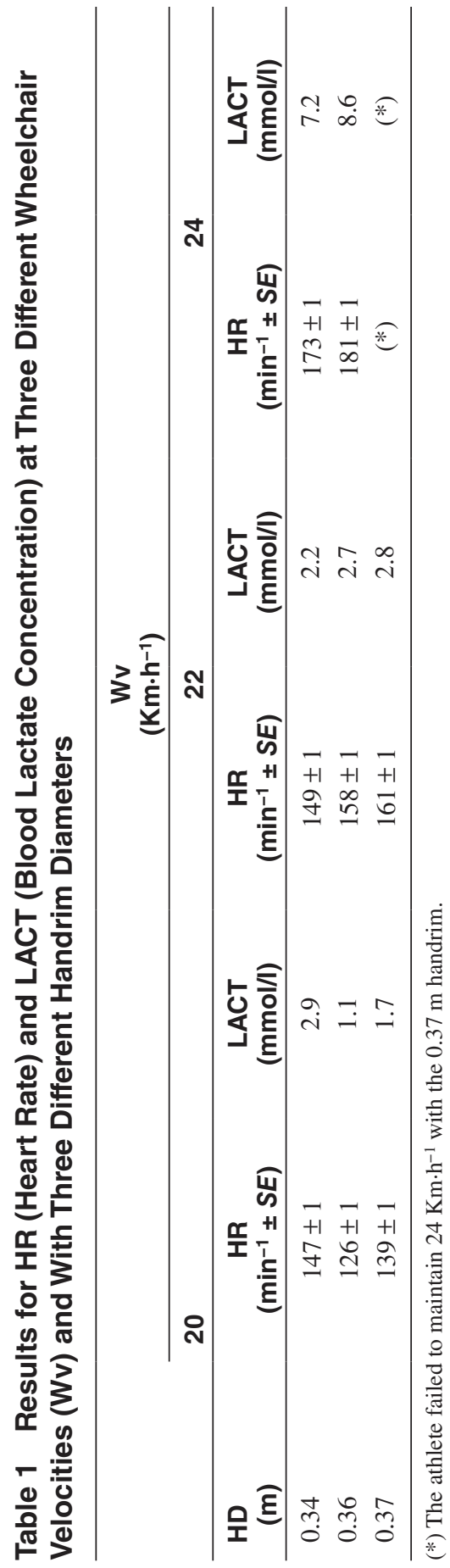


The findings show that the most adequate diameter differs depending on the speed. For the studied athlete, the most efficient handrims at $20 \mathrm{Km} \cdot \mathrm{h}^{-1}$ were those with a $0.36 \mathrm{~m}$ diameter $\left(\mathrm{HR}=126 \mathrm{~min}^{-1}\right.$, LACT $\left.=1.1 \mathrm{mmol} \cdot \mathrm{1}^{-1}\right)$, while $0.37 \mathrm{~m}$ handrims were moderately efficient $\left(\mathrm{HR}=139 \mathrm{~min}^{-1}, \mathrm{LACT}=1.7 \mathrm{mmol} \cdot \mathrm{l}^{-1}\right)$, and $0.34 \mathrm{~m}$ handrims were the least efficient $\left(\mathrm{HR}=147 \mathrm{~min}^{-1}, \mathrm{LACT}=2.9 \mathrm{mmol} \cdot \mathrm{l}^{-1}\right)$. When speed was increased to $22 \mathrm{Km} \cdot \mathrm{h}^{-1}$, a change was noticed: $0.34 \mathrm{~m}$ handrims became the most efficient $\left(\mathrm{HR}=149 \mathrm{~min}^{-1}, \mathrm{LACT}=2.2 \mathrm{mmol} \cdot \mathrm{l}^{-1}\right)$, while $0.36 \mathrm{~m}$ handrims had intermediate efficiency $\left(\mathrm{HR}=158 \mathrm{~min}^{-1}\right.$ and LACT $\left.=2.7 \mathrm{mmol} \cdot \mathrm{l}^{-1}\right)$, and $0.37 \mathrm{~m}$ handrims became the least efficient, but with not too much of a difference $\left(\mathrm{HR}=161 \mathrm{~min}^{-1}, \mathrm{LACT}=2.8 \mathrm{mmol} \cdot \mathrm{l}^{-1}\right)$. Lastly, at $24 \mathrm{Km} \cdot \mathrm{h}^{-1}$ the greatest efficiency of $0.34 \mathrm{~m}$ handrims was confirmed $\left(\mathrm{HR}=173 \mathrm{~min}^{-1}\right.$, LACT $=7.2$ $\left.\mathrm{mmol} \cdot \mathrm{l}^{-1}\right)$ versus $0.36 \mathrm{~m}$ handrims $\left(\mathrm{HR}=181 \mathrm{~min}^{-1}, \mathrm{LACT}=8.6 \mathrm{mmol} \cdot \mathrm{l}^{-1}\right)$ and $0.37 \mathrm{~m}$ handrims, with which it was impossible to maintain the preset speed.

\section{Discussion}

Before discussing the results, it is important to note that the conclusions of this paper are drawn from the study of a single athlete. Thus, even if some general conclusions could be reached and recommendations given for the use of the methodology in the study of other athletes, it should be pointed out that individual differences may alter results significantly, even between athletes from the same functional class. Nevertheless, it can be interesting to emphasize that the results for this elite athlete are in line with general results obtained by other authors with nonelite wheelchair athletes in previous laboratory studies.

As expected, stroke frequency (SF) rises and push time (PT) drops while wheelchair velocity (Wv) increases on the athletic racing track. In addition, an increase in handrim diameter (HD) affects both variables, push time and stroke frequency.

However, the modification of the handrim diameter produces the same effect on both variables but in varying degrees. While the maximum differences in stroke frequency, due to a $0.01 \mathrm{~m}$ increase in handrim diameter, are about $6 \%$ (for the highest speed), push time differences come to $27 \%$, which is very similar to an increase in wheelchair velocity from 20 to $24 \mathrm{Km} \cdot \mathrm{h}^{-1}(25 \%)$.

Based on the results, at $24 \mathrm{Km} \cdot \mathrm{h}^{-1}$ and with $0.37 \mathrm{~m}$ handrims, the athlete had a $0.173 \mathrm{~s}$ push time while with $0.36 \mathrm{~m}$ handrims, at the same speed, push time was $0.226 \mathrm{~s}$, that is, $27 \%$ more time to apply the necessary mechanical impulse. This longer push time with the smaller handrim diameter (HD) could allow the athlete to apply the same mechanical impulse with smaller values of muscular force. As Veeger et al. (1992) and Woude et al. (1988) conclude, the smaller handrims could partially account for the lower physical strain in high-intensity efforts, reflected by a lower heart rate and a lower (but not statistically proved) blood lactate concentration.

This lower physical strain found with smaller handrims, which is related to a lower stroke frequency but in this study mainly to a longer push time in each cycle, could be interpreted, as Woude et al. (1988) point out, as higher mechanical propulsion efficiency. It seems obvious that despite the fact that larger handrims 
have a longer lever arm, their greater tangential velocity could be a limiting factor during handrim propulsion at high speeds.

Regarding the choice of handrim diameters, at the highest speed $\left(24 \mathrm{Km} \cdot \mathrm{h}^{-1}\right)$ increases in handrim diameter of $2 \mathrm{~cm}$ (from $0.34 \mathrm{~m}$ to $0.36 \mathrm{~m}$ ) affect heart rate up to $7 \mathrm{~min}^{-1}(4 \%)$ and blood lactate in $1.4 \mathrm{mmol} \cdot \mathrm{l}^{-1}(18 \%$, but not statistically proved). This modification can be highly relevant when racing at speeds really close to the anaerobic threshold, bearing in mind that surpassing such a threshold may mean not being able to continue with the same effort intensity in endurance races.

Something that can be surprising is that the smaller handrims $(0.34 \mathrm{~m})$ are less efficient at the lowest analyzed speed in the current study $\left(20 \mathrm{Km} \cdot \mathrm{h}^{-1}\right)$ when at the highest speeds $\left(22 \mathrm{Km} \cdot \mathrm{h}^{-1}\right.$ y $\left.24 \mathrm{Km} \cdot \mathrm{h}^{-1}\right)$, they are most efficient and they cause less physical strain. This finding (detected as a significant interaction between HD and Wv) could be related to the existence of an optimal handrim diameter for each different speed, being any other handrim diameter less efficient at that specific speed and cause more physical strain.

Based on the findings, one could conclude that choosing the most adequate handrim diameter could enhance the mechanical efficiency of the athlete-wheelchair duet and optimize the speed that the athlete can keep, based on the power and endurance of the human engine in its current condition.

For the studied athlete, his anaerobic threshold in the last stage of the season was measured at $172 \mathrm{~min}^{-1}$ heart rate. With the information drawn from the study, it was calculated that, for that effort intensity, a speed close to $23 \mathrm{Km} \cdot \mathrm{h}^{-1}$ could be maintained with the $0.36 \mathrm{~m}$ diameter handrim, whereas with the $0.34 \mathrm{~m}$ diameter, the speed could be very close to $24 \mathrm{Km} \cdot \mathrm{h}^{-1}$. In a half marathon race, choosing the right diameter could well mean a final advantage of about $1 \mathrm{Km}$ or $2.5 \mathrm{~min}$.

It has been demonstrated that heart rate-a good indicator of physical strain caused by wheelchair propulsion (Janssen et al., 2001) — is affected by the diameter of the handrim. In addition, heart rate variation-as a response to different handrims - could be similar to that of blood lactate concentration. Although it is easier and less invasive to only measure heart rate, this measurement could be insufficient when evaluating the influence of a change in handrim diameters. A modification in stroke frequency could affect the force applied in each stroke and consequently the muscular work done, this being likely to influence blood lactate concentration.

Finally, the analysis methodology was useful to the athlete and helped him choose the handrim diameter to use for training purposes and even for competition throughout the season. The athlete's achievements and especially breaking some world records on track and on road indicate that handrim diameter optimization could be highly profitable in sport terms.

\section{Acknowledgment}

This project was performed at the University of Valencia and supported by a grant of the Spanish Paralympic Committee (CPE), the Spanish Federation for People with Physical Disability (FEDDF), and the Valencian Federation of Adapted Sports (FESA). The authors greatly acknowledge the support given by these entities. 


\section{References}

Chow, J.W., Millikan, T.A., Carlton, L.G., Morse, M.I., \& Chae, W.S. (2001). Biomechanical comparison of two racing wheelchair propulsion techniques. Medicine and Science in Sports and Exercise, 33(3), 476-484.

Goosey, V.L., Fowler, N.E., \& Campbell, I.G. (1997). A Kinematic analysis of wheelchair propulsion techniques in senior male, senior female, and junior male athletes. Adapted Physical Activity Quarterly, 14, 156-165.

Goosey, V.L., \& Campbell, I.G. (1998). Pushing economy and propulsion technique of wheelchair racers at three speeds. Adapted Physical Activity Quarterly, 15, 36-50.

Goosey, V.L., Campbell, I.G., \& Fowler, N.E. (2000). Effect of push frequency on the economy of wheelchair racers. Medicine and Science in Sports and Exercise, 32(1), 174-181.

Guo, L.Y., Su, F.C., \& An, K.N. (2006). Effect of handrim diameter on manual wheelchair propulsion: Mechanical energy and power flow analysis. Clinical Biomechanics (Bristol, Avon), 21(2), 107-115.

Janssen, T., Dallmeijer, A., \& Woude, L.H.V.v.d. (2001). Physical capacity and race performance of handcycle users. Journal of Rehabilitation and Development., 38(1), $33-40$.

McLaurin, C.A., \& Brubaker, C.E. (1991). Biomechanics and the wheelchair. Prosthetics and Orthotics International, 15(1), 24-37.

Okawa, H., Tajima, F., Makino, K., Kawazu, T., Mizushima, T., Monji, K., et al. (1999). Kinetic factors determining wheelchair propulsión in maratón racers with tetraplejia. Spinal Cord, 37(8), 542-547.

Traut, L., \& Schmauder, M. (1993). Ergonomic design of the hand-machine interface for wheelchairs. In L.H.vD Woude et al., Ergonomics of manual wheel-chair propulsion: State of the art (pp.335-348). Amsterdam: IOS Press.

Veeger, H.E.; Woude, L.H.V.v.d.; Rozendal, R.H. (1989). The effect of rear wheel camber in manual wheelchair propulsion. Journal of Rehabilitation Research and Development, 26(2), 37-46.

Veeger, H.E.; Woude, L.H.V.v.d.; Rozendal, R.H. (1992). Effect of hand rim velocity on mechanical efficiency in wheelchair propulsion. Medicine and Science in Sports and Exercise, 24(1), 100-107.

Wang, Y.T., Deutsch, H., Morse, M., Hedrick, B., \& Millikan, T. (1995). Three-dimensional kinematics of wheelchair propulsion across racing speeds. Adapted Physical Activity Quarterly, 12, 78-89.

Woude, L.H.V.v.d., Groot, G.d., Hollander, A.P., Ingen Schenau, G.J.v., \& Rozendal, R.H. (1986). Wheelchair ergonomics and physiology of prototypes testing. Ergonomics, 29(1), 1561-1573.

Woude, L.H.V.v.d. (). Veeger, H.E., Rozendal, R.H., Ingen Schenau, G.J.v., Rooth, F., \& Nierop, P.V. (1988). Wheelchair racing: effects of rim diameter and speed on physiology and technique. Medicine and Science in Sports and Exercise, 20(5), 492-500.

Woude, L.H.V.v.d. (1989). Manual wheelchair propulsion: An ergonomic perspective. $\mathrm{PhD}$ Thesis, Vrije Universiteit Amsterdam. Amsterdam: Free University Press.

Woude, L.H.V.v.d., Veeger, H.E., Rozendal, R.H., \& Sargeant, A.J. (1989). Optimum cycle frequencies in hand-rim wheelchair propulsion. Wheelchair propulsion technique. European Journal of Applied Physiology and Occupational Physiology, 58(6), 625632.

Woude, L.H.V. d., Veeger, H.E.J., \& Dallmeijer, A.J. (2000). Manual wheelchair propulsion. In M. Vladimir \& M. Zatsiorsky, Biomechanics in sport: Performance enchancement and injury prevention (p. 609-636). Champaign, IL: Human Kinetics. 